\title{
Memórias de Ex-alunos do Colégio de Aplicação da Bahia: contribuições para a História da Educação Matemática
}

\author{
Memories of the Former Students of Colégio de Aplicação da Bahia: \\ contributions to History of Mathematics Education
}

Diogo Franco Rios*

\begin{abstract}
Resumo
Este trabalho se inscreve no âmbito das perspectivas historiográficas que buscam contemplar, em suas produções, a história, a memória e a identidade de grupos que têm sido menos valorizados, atribuindo-lhes um status de igual valor às fontes, perspectivas e personagens que tradicionalmente têm sido tratadas como centrais. Pela constituição de fontes orais, se favorece que as perspectivas apontadas pelos ex-alunos emerjam, oferecendo contribuições que enriquecem os trabalhos em História da Educação Matemática. Trata-se de uma contribuição que apresenta interpretações peculiares àquilo que já vem sendo estudado a respeito do processo de modernização do ensino de matemática no Colégio de Aplicação da Universidade da Bahia. Dois elementos são acrescentados a partir das narrativas dos ex-alunos: a consideração de que a modernização não era um fenômeno afeito somente à matemática, mas às diversas disciplinas e práticas do Colégio e a identificação da professora Maria Augusta de Araújo Moreno como destacada referência da modernização da matemática no Colégio.
\end{abstract}

Palavras-chave: História da Educação Matemática. História Oral. Memória. Alunos. Colégio de Aplicação da Bahia.

\begin{abstract}
This work falls under historiographical perspectives that seek to include, in their productions, history, memory, and identity of groups that have been less valued, by assigning them a status equal to sources, perspectives and characters that have traditionally been treated as centrals. The constitution of oral sources provides to emerge opportunities identified by formed students, offering contributions to those who traditionally served as a source for researches in History of Mathematics Education. It is a contribution which adds additional interpretations to what has already been studied and enriches historical analysis about the process of modernization in mathematics teaching at Colégio de Aplicação da Universidade da Bahia. Two elements could be considered from the testimony of former students: considering that modernization was not a phenomenon accustomed only to mathematics, but to the various disciplines and practices of the Colégio and the identification of teacher Maria Augusta de Araújo Moreno as a highlighted reference of mathematics modernization at the Colégio.
\end{abstract}

Keywords: History of Mathematics Education. Oral History. Memory. Students. Colégio de Aplicação da Bahia.

\section{Apresentando o tema: a voz dos ex-alunos}

\footnotetext{
* Doutor em Ensino, Filosofia e História das Ciências pela Universidade Federal da Bahia (UFBA) e Universidade Estadual de Feira de Santana (UEFS). Docente na Universidade Federal de Pelotas (UFPel), Pelotas, Rio Grande do Sul, Brasil. Endereço para correspondência: Campus Capão do Leão, s/n ${ }^{\circ}$, Instituto de Física e Matemática, prédio 05, sala 302, CEP 96010-971, Capão do Leão, Rio Grande do Sul, Brasil. E-mail: riosdf@hotmail.com.
} 
Este trabalho ${ }^{1}$ constitui-se em um desdobramento de uma pesquisa (RIOS, 2012a) que analisou memórias de ex-alunos do Colégio de Aplicação da Universidade da Bahia (doravante, CA) sobre o ensino de Matemática Moderna (doravante, MM) entre os anos 1966 e 1976, e produziu fontes históricas a partir das suas perspectivas a respeito daquele processo educacional. Trata-se de um trabalho inscrito no âmbito das perspectivas historiográficas que, nas últimas décadas, vem incorporando uma variedade de temas que também trazem consigo a pluralidade e a diversidade de abordagens teórico-metodológicas (BARROS, 2004). Dessa pluralidade, destacam-se aquelas que reconhecem a importância de contemplar, nas análises que realizam, a história, a memória e a identidade de grupos que têm sido menos valorizados, a partir dos seus próprios discursos e da sua própria voz, atribuindo-lhes uma importância que nem sempre lhes foi atribuída, seja pela história tradicional, seja pela memória oficial (POLLAK, 1989, 1992). No âmbito da história da educação, por exemplo, é reconhecida a pouca valorização conferida aos alunos e seus discursos na produção das análises, o que pode ser explicado, em parte, pela usual escolha dos pesquisadores da área. Costuma-se encontrar análises concentradas, prioritariamente, em aspectos relacionados aos líderes e personagens proeminentes dos projetos educacionais, sejam eles legisladores, lideranças, diretores ou professores, tomando como fontes privilegiadas, além dos documentos oficiais, os discursos e documentos pessoais desses personagens.

Pode parecer inusitado considerar as memórias dos ex-alunos como memórias marginalizadas (se consideramos as memórias políticas, por exemplo), mas a ausência de documentos de alunos e a pouca frequência de suas versões sobre as experiências vividas nos processos educacionais se constituem em marcas importantes nas análises historiográficas em que essa lacuna tem sido reconhecida, mais recentemente (CASSAB, 2010).

Essa ausência também pode ser explicada como consequência decorrente da dificuldade de acesso ou, mesmo, da inexistência, nos acervos institucionais e pessoais, de documentos referentes às práticas escolares específicas dos alunos. Em muitos casos, isso representa um desafio adicional às pesquisas que pretendam tomar fontes dessa natureza para realização de suas análises. De um modo mais geral, se referindo às práticas escolares cotidianas, Julia (2001) já havia apontado a dificuldade de se ter acesso aos registros relacionados com práticas culturais escolares e, no caso das pesquisas históricas no âmbito do ensino de matemática, essa dificuldade também já foi reconhecida (VALENTE, 2005).

\footnotetext{
${ }^{1}$ Uma versão bem reduzida foi apresentada, anteriormente, em um evento científico (RIOS, 2012b)
} 
Trago em pauta a importância de se enfrentar tais desafios e contornar essa distorção na utilização das fontes históricas. Ao cumprir o expediente de confrontar a posição que tem tomado certas fontes como hegemônicas, e ao ampliarmos o uso das interpretações e versões de ex-alunos, personagens que também participaram diretamente dos processos educacionais, pode-se oferecer à historiografia da educação matemática novas perspectivas às análises existentes, com o esclarecimento de questões que as fontes prioritariamente usadas não têm oferecido.

A história oral (THOMPSON, 2002; PORTELLI, 2010) pode ser uma via de produção de fontes dessa natureza, além de oferecer "uma oportunidade para narradores relativamente obscuros serem canonizados no discurso público: um relato público realizado por pessoas que raramente têm a oportunidade de falar publicamente" (PORTELLI, 2010, p. 186). Ao defender tal compromisso da história oral, Portelli não estava focalizando, especificamente, os ex-alunos, mas se referia à diversidade de sujeitos que não ocupam lugares centrais nos diversos temas analisados pela historiografia. Em sua prática na produção de fontes orais a partir de sujeitos comuns, explicita o quanto aquilo que contam pode contribuir para o enriquecimento da explicação histórica que se desenvolve a partir de fontes mais tradicionais e a partir da perspectiva de sujeitos e grupos mais proeminentes ou que ocupam posições sociais legitimadas como mais centrais.

Sob outro aspecto, contemplar as narrativas ${ }^{2}$ dos ex-alunos, pode ser interpretado como um exercício analítico que se dedica a considerar as perspectivas dos sujeitos infames da educação. Infames não no sentido lato, mas como os entende Foucault (1992), ou seja, sujeitos cujas experiências são costumeiramente ignoradas, somente se fazendo registrar quando, por um acaso do destino, tiverem suas trajetórias confrontadas com os mecanismos do poder. No caso da escola, por exemplo, com frequência ficam registrados apenas os casos excepcionais: nas ocasiões em que o aluno comum, por desobedecer a norma, descumprir as regras institucionais, praticar algo que demande um castigo ou cometer alguma infração cuja punição possa se transformar em um caso exemplar para os outros, ele terá seu nome destacado ou retirado da esfera anônima de sua prática cotidiana de sala de aula e será alçado a uma condição excepcional. Exceto em casos como esses, sua trajetória passa incólume pelo

\footnotetext{
${ }^{2}$ Aqui, as narrativas são consideradas como elaborações produzidas pelos entrevistados a respeito daquilo que viveram e que estão impregnadas pelo modo como ainda se relacionam com seu passado e pelos significados que lhe atribuem no tempo presente. Além disso, é preciso dizer que tais elaborações são produzidas durante ocasiões (as entrevistas) em que certa tensão está estabelecida, seja por condicionantes sociais que ainda regulam o entrevistado, seja pela presença de um ouvinte (pesquisador) que não lhe é familiar. Para mais reflexões a respeito, ver: (PORTELLI, 2001, 2010).
} 
registro escolar, desaparecendo no volume de fichas, planilhas, diários e notas que guardam o registro da aprovação ou reprovação dos alunos ao final de cada período letivo.

O que defendo ao longo deste trabalho é que, no caso da História da Educação e, mais especificamente, da Educação Matemática, contemplar a perspectiva de ex-alunos é tratá-los como sujeitos que também tiveram lugar privilegiado no processo histórico. É, em grande medida, contemplar a singularidade de sua posição no cotidiano escolar e as implicações decorrentes disso, que vão desde a abertura de um campo de possibilidades de vivências cotidianas, distintas das experimentadas pelos professores e por outros personagens educacionais, até a imposição de limitações explicativas que se estabelecem em função da sua condição de estudantes. E tudo isso sem depender de sua captura por alguma estrutura de poder ou situação de excepcionalidade que lhes confira alguma fama ou importância extrínseca.

Trabalhar com essa natureza de fontes se sustenta no fato de que cada grupo, por ocupar um lugar específico, produz uma perspectiva diferente, carregada de traços relacionados à função que desempenhou e à posição que ocupou naquele processo, tornando plausível reconhecer que memórias de ex-alunos representam uma perspectiva importante em análises históricas relacionadas às disciplinas escolares. E não como material secundário, mas oferecendo perspectivas peculiares que podem servir de fonte alternativa para os trabalhos de História da Educação Matemática.

Não pretendo sugerir que há algum tipo de contradição ou antagonismo entre as fontes relacionadas a professores e outros agentes educacionais e fontes relacionadas aos ex-alunos, mas destacar o potencial explicativo e compreensivo existente por trás dessa variedade de fontes. Trata-se de considerar que a relativa obscuridade em que são conservadas as experiências educacionais dos estudantes, em consequência de não terem exercido funções de relevância institucional nos ambientes escolares (como o desempenho de certos papéis sociais, pelo professor, por exemplo), não deve ser tomada como evidência de sua condição secundária, da sua impertinência na construção histórica ou da sua incapacidade de enriquecerem a análise histórica, mas como uma marca do lugar social desses sujeitos.

Reconhecemos que, dificilmente, um aluno terá acompanhado aspectos relacionados aos processos de planejamento e elaboração de propostas educacionais de modo a nos oferecer um material substantivo sobre esse tipo de prática. A contribuição deles se estabelece em outra direção, oferecendo narrativas carregadas de elementos associados à "assimilação efetiva do curso, e a aculturação resultante" (CHERVEL, 1990, p. 208) a partir daquilo que era praticado nas aulas, podendo ser, nesse caso, consideradas como narrativas apropriadas 
para análises históricas interessadas nesses aspectos de uma disciplina escolar. Ao considerar que essas fontes possibilitam discutir traços de assimilação e aculturação escolar, entretanto, não estou defendendo que seja adequado ou indicado usá-las para avaliar a eficácia ou não de práticas de ensino ou de projetos educacionais. Diferente disso, trata-se de considerar que as fontes relativas a ex-alunos podem ser consideradas como material privilegiado no caso de investigações que se proponham a compreender os entremeios e correlações das ações dos líderes educacionais e professores, alguns efeitos cotidianos de suas propostas educacionais, implicações dos objetivos e esforços que foram empreendidos para cumpri-los e, de modo mais objetivo, as representações que os ex-alunos constroem a respeito, explicitando os significados que atribuem a tais práticas, propostas, conteúdos, etc.

Com o objetivo de valorizar a utilização de fontes de ex-alunos nas investigações que vêm sendo realizadas no âmbito da História da Educação Matemática, com vistas a ampliar a compreensão histórica a respeito de práticas educativas da disciplina, abordo um caso específico. Nessa pesquisa, as fontes históricas de ex-alunos foram utilizadas para produção de uma análise a respeito do ensino de Matemática Moderna no Colégio da Aplicação vinculado à Universidade Federal da Bahia entre as décadas de 1960 e 1970, oferecendo elementos inéditos e enriquecedores para a historiografia existente. Trata-se de uma contribuição que apresenta interpretações adicionais àquilo que já vem sendo apontado por trabalhos que exploram fontes mais tradicionais e que, ao se juntar ao que vem sendo analisado, enriquecem a análise histórica a respeito daquele processo educacional e, com isso, trazem novidades importantes. Neste caso, posso destacar dois elementos novos que somente são considerados a partir das narrativas dos estudantes. O primeiro é a consideração de que a modernização não era um fenômeno afeito somente à matemática ${ }^{3}$, mas a diversas disciplinas e práticas do Colégio, especialmente nas ciências experimentais, e o segundo é a identificação da professora Maria Augusta de Araújo Moreno como uma destacada referência quanto à Matemática Moderna no Colégio. Ambos os aspectos só apareceram a partir do trabalho com as fontes dos ex-alunos. Mais adiante, abordo mais detidamente esses dois pontos.

\section{O Colégio de Aplicação da Universidade da Bahia}

\footnotetext{
3 Aqui, moderno não se restringirá ao adjetivo associado à Matemática Moderna. Os termos moderno, modernizador ou modernização estão sendo tomados como características peculiares presentes em certas práticas e construídas nas memórias dos entrevistados, e não como conceitos universais estabelecidos a priori. Trata-se de uma concepção que assume o moderno como um rompimento com o passado (LE GOFF, 1984; RODRIGUES, 1994).
} 
O Colégio de Aplicação começou a funcionar em 1949. Teve como fundador e primeiro diretor o professor Isaías Alves de Almeida e, como primeira subdiretora, a professora Martha Dantas. Começou com uma turma de $1^{\circ}$ ano ginasial e, a partir de 1953, passou a ter turmas do segundo ciclo do secundário, sendo uma de Estudos Clássicos e outra de Científico (HISTÓRICO, 1965). Inicialmente, eram oferecidas 30 vagas e, posteriormente, passaram a ser 60 vagas, sendo o Exame de Admissão o sistema geral de ingresso. No caso do segundo ciclo, também era possível ingressar no $1^{\circ}$ ano a partir de exame de admissão similar, feito para as vagas remanescentes. O Colégio nunca teve curso primário.

No primeiro período de sua existência, funcionou nas instalações da Faculdade de Filosofia da Universidade da Bahia (doravante, FF), no bairro de Nazaré, em Salvador. Em 1967, transferiu-se para uma sede própria construída no bairro do Canela, também na capital baiana. Depois de 27 anos de funcionamento, em 1976, encerrou suas atividades por decisão do Reitor da Universidade Federal da Bahia ${ }^{4}$, professor Lafayette Pondé, após um processo de desaceleração de suas atividades, iniciado em 1973.

Entre seus principais objetivos, destaca-se a proposta de possibilitar a prática docente dos alunos matriculados no Curso de Didática, uma das cadeiras pedagógicas a serem cursadas pelos licenciandos da FF (BERTANI, 2012). Em seu quadro docente, tinha duas categorias de professores: os professores assistentes das cadeiras de Didática, vinculados à Universidade, e os professores regentes do próprio Colégio, que deveriam para isso possuir o título de licenciado oferecido por uma faculdade de filosofia (REGIMENTO, 1944).

Nas memórias de alguns personagens que participaram, liderando e organizando propostas modernizadoras e experimentais na Bahia, o Colégio de Aplicação teve uma condição privilegiada para a implementação de propostas para a matemática, traço que também é reconhecido pela historiografia existente (DANTAS, 1993; GARNICA, 2008; MATTOS, 2002). Sem explorar a condição supostamente privilegiada do CA discuto alguns elementos das memórias de ex-alunos sobre o ensino da MM na instituição.

\section{Associação entre a modernização do ensino de matemática, de ciências e outras disciplinas}

Para a realização deste trabalho, selecionei alguns elementos que oferecem uma ampliação à historiografia da educação matemática na Bahia que, nos trabalhos disponíveis,

\footnotetext{
${ }^{4}$ Com a reforma universitária, em 1968, a Universidade da Bahia assumiu a nomenclatura Universidade Federal da Bahia.
} 
reconhece que, assim como em outros estados do país, na segunda metade da década de 1960 houve uma intensificação do processo de institucionalização dos padrões modernos no âmbito das ciências experimentais e da matemática, a partir da convergência de diversos fatores e circunstâncias (DIAS, 2008; BÚRIGO, 2010).

No caso da Bahia, a historiografia destaca o papel que a Secção Científica de Matemática do Centro de Ensino de Ciências da Bahia - CECIBA (FREIRE, 2009; FREIRE; DIAS, 2010) e o Instituto de Matemática e Física da Universidade da Bahia (DIAS, 2008) tiveram para a institucionalização de padrões modernos da matemática no Estado.

Em função dos objetivos declarados nos trabalhos relacionados à temática e da especificidade de suas fontes, as análises produzidas não se ativeram, demoradamente, às possíveis associações que existiram entre os processos de institucionalização da matemática e aqueles relativos às ciências experimentais. Esse aspecto poderia associar as modernizações relacionadas ao ensino de matemática a um bojo mais amplo, àquelas praticadas em diversas outras disciplinas escolares, de modo que se considerasse a interação entre os movimentos da sociedade, as transformações no sistema educacional e o espírito da época, e não como uma iniciativa isolada.

Nesse sentido, a memória dos ex-alunos do CA pode contribuir ao acrescentar suas perspectivas peculiares. Um traço que merece ser destacado é que, para eles, a implementação de padrões modernos para o ensino de matemática ficou evidenciada a partir da atuação de seus professores que, por vezes, discutiram ou explicitaram as mudanças que estavam promovendo e estabelecendo em suas aulas. Outro traço advém das comparações que eles mesmos faziam entre as experimentações que estavam sendo realizadas no CA e os padrões de ensino praticados em outras instituições escolares a que tinham acesso por intermédio de parentes ou colegas com quem conversavam.

Na disciplina português, por exemplo, considerava-se moderno um ensino voltado para leitura, interpretação e produção de textos que, segundo Eduardo Silva, se distinguia muito do modelo de ensino praticado em outras escolas da cidade. Ele toma como parâmetro para essa comparação o ensino de português que era vivenciado por sua irmã no Instituto Feminino da Bahia 5 .

[...] eu pego o curso de português do Aplicação, porque esse eu me lembro bem! Você tinha seis aulas de português por semana e você tinha leitura permanente e leitura em sala, né, você tinha texto pra ler, o tempo todo, quer dizer, eu sou cinco anos mais moço que a minha irmã do meio, que estudou no Instituto Feminino da Bahia [...] um colégio das mocinhas de classe média, etc., etc., e minha irmã,

\footnotetext{
${ }^{5}$ O Instituto Feminino da Bahia foi fundado em 1923 e tinha, como principais objetivos, oferecer uma formação moral e religiosa às alunas, além de uma preparação profissional (PASSOS, 1994).
} 
coitada, sofria e odiava português, por que? Porque o ensino que ela fazia de português era um ensino em que ela tinha cadernos específicos pra fazer análise sintática [...] Sabe, né, essa coisa chatérrima que era análise sintática, você ficar descobrindo ao estilo latino, certo, o que é sujeito o que é predicado, o que é não sei o que [...] Não tô dizendo que isso não te ajuda a escrever e a ler, não. Mas não é o essencial, eu acho que não é.

Então, o Aplicação trabalhou o tempo todo no ensino de português, trabalhava o tempo todo com leitura e muita redação, então, você lia e escrevia o tempo todo, você lia e comentava texto, você lia e redigia, sempre isso, né, e muito pouco, eu diria, o suficiente, a gramática classicamente pensada, né, então, o que era isso, isso lhe dava acesso a um conjunto de cronistas e contistas, famosos na época [...] (SILVA, 2010, p. 6-7).

Outro elemento a destacar é a existência do CECIBA (1965-1969), identificado nas memórias dos entrevistados, principalmente, pela intensificação de práticas modernizadoras nas aulas de matemática simultaneamente à havida no ensino de física, química e biologia.

Ainda que as inovações fossem realizadas sob a influência do CECIBA, eram praticadas pelos seus próprios professores ou pelos estagiários da $\mathrm{FF}$ que estiveram vinculados, direta ou indiretamente, ao Centro. Isso ajuda a explicar o fato de não ter ficado claro para eles que determinadas ações estivessem relacionadas, pedagogicamente, com o CECIBA. Também, não se pode esperar que os ex-alunos tenham se ocupado de entender, à época, pelo menos detalhadamente ou de modo tão sistemático, o que representavam certas práticas pedagógicas, objetivos, resultados, bem como o período específico em que foram implementados, como talvez coubesse aos professores e outros personagens educacionais ligados à Instituição saber.

Com relação ao ensino de ciências experimentais, as experimentações que vinham sendo praticadas no CA, pelo menos desde o início da década de 1960 e que se intensificaram com a criação do CECIBA, caracterizavam-se, basicamente, pela utilização de livros de ciências com base em projetos norte-americanos ${ }^{6}$ e pela utilização do Método Keller (SERPA, 1993), que propunha associar aulas teóricas com atividades práticas, inclusive, com a utilização de laboratórios para a realização de experimentos dessas disciplinas.

A identificação dessa intensificação simultânea entre as experimentações no ensino de ciências experimentais e na matemática sinaliza para existência de um projeto modernizador mais amplo que se realizava no $\mathrm{CA}$, e que possibilitou que a $\mathrm{MM}$ encontrasse na instituição um terreno propício, um conjunto de condições para ser implementada, uma convergência de

\footnotetext{
${ }^{6}$ Em função da intensificação de investimentos no ensino de ciências de nível médio foram criados projetos para reformar de ensino médio norte-americano, a partir do final dos anos cinquenta, dentre os quais o Physical Sciences Study Committee (PSSC), o Biological Sciences Curriculum Study (BSCS), o Chemical Bond Approach (CBA), o School Mathematics Study Group (SMSG), financiados pela National Science Foundation. Esses Projetos foram implementados em vários países, dentre eles o Brasil (OLIVEIRA FILHO, 2009).
} 
padrões modernos e experimentais que eram praticados em outras disciplinas, e que abriam o flanco para que ela também se implementasse daquela forma.

A importância da associação indicada entre o ensino de ciências e de matemática se torna maior se considerarmos que as iniciativas associadas à matemática não figuram para os ex-alunos como mais marcantes que aquelas relacionadas com as disciplinas de ciências, que tinham aulas teóricas e práticas. Para eles, a modernização do ensino de matemática fica secundarizada se comparada àquelas praticadas nas outras disciplinas e, especialmente, nas disciplinas de ciências experimentais. A relevância por vezes atribuída na historiografia àquela proposta feita pela matemática fica relativizada na memória dos ex-alunos, por reconhecerem o conjunto de outras tantas práticas inovadoras e experimentais que ali se realizavam.

\begin{abstract}
A gente tinha aulas lá, no formato da Universidade Federal, que era, por exemplo, você ter aulas normais de manhã e você escolhia as matérias eletivas ou optativas, como se fosse na Universidade, aí você tinha matéria que tinha um peso, as que você podia pegar e as que você não podia pegar, aí a gente tinha... pra você ter uma ideia, a gente tinha que pegar duas por semestre, tinha artes industriais, [...] você tinha aulas de história da arte, através de slides - imagine isso no início da década de 70 -, você aprendendo Grécia, Roma, os grandes artistas do Renascimento, através de slides, você tinha taquigrafia, [...] iniciação artística [...]

Outra característica muito interessante da Escola é que você tinha testes de língua estrangeira, no primeiro ano [...] e aí um garoto do quinto ano... do que seria hoje a quinta série, primeiro ano de ginásio, fazia um teste - mas se ele estudava inglês desde garoto - ele era nivelado aos caras que estavam no segundo grau, ele frequentava aulas de inglês com esses caras, na mesma sala, era um pivetinho de onze anos com uns caras já barbados [...] Essas aulas eram à tarde e isso permitia você frequentar uma outra sala, com outras pessoas, porque de manhã era o ensino natural, normal.

[...] Ah, tinha teatro também, outra matéria optativa, eu cheguei a fazer teatro lá [...] a gente saía da Escola e atravessava a rua, andava uns trezentos metros e ia pra Escola de Teatro tomar aula de teatro na Escola de Teatro, imagine, cara... (CARVALHO, 2010, p. 5, 14).
\end{abstract}

Eunice Kalil, por sua vez, conta que preferia as aulas de geografia, nas quais a professora Anália lhe proporcionava um "sabor de aventura" (KALIL, 2010, p.3), apesar de reconhecer que a professora de história era considerada como muito interessante por seus colegas.

Eu lembro muito de professora Anália, que ensinava geografia, porque a professora Anália... porque [em] geografia a gente viu os outros geossistemas... porque assim, estudar estepes, não era estudar estepes, era estudar o mundo onde tinha as estepes, entendeu? Lembro muito dessa coisa do sabor de abertura de estudar o mundo via geografia, entendeu?

[...] Eu acho que história pra mim, embora eu tivesse uma professora que era considerada muito interessante, exigente, mas nunca foi para mim essa possibilidade de abertura como foi o ensino de geografia..., geografia humana, geografia política, a forma como professora Anália, e também ela era uma mulher muito... (KALIL, 2010, p. 3). 
Sua memória aponta para uma modernização importante do ensino de geografia, que rompia com o padrão tradicional da disciplina, pautava pela classificação, passando a comprometer-se com a compressão dos processos geográficos que associam, mais diretamente, a geografia física com a humana e a política (CASTROGIOVANNI, 2000).

Com relação ao ensino de ciências experimentais, destaco a narrativa de Sueli Prata, aluna do Colégio de Aplicação de 1963 a 1969:

\begin{abstract}
Agora, se você quer saber, eu realmente acho que tem a ver com essa coisa de ser teoria e prática [...] mas, acho, por exemplo, que das quatro disciplinas, exatamente, pela disciplina matemática não ter esse tipo de abordagem teórica e prática, é a que deixou mais a desejar, no conjunto dessas disciplinas que não eram humanas, nem língua, tá certo, as outras três a gente gostava mais do que gostava da matemática e eu credito a isso, a você ter um material didático que pressupõe uma prática de ensino-aprendizagem bifurcada, teoria e prática, de uma forma muito sedimentada, então, era muito legal você fazer uma experiência prática e depois você estudar aquela coisa [que] você viu, você tinha memória visual, e na matemática você não tinha isso (PRATA, 2010, p. 19-20).
\end{abstract}

Para ela, faltava à matemática as inovações propostas pelas disciplinas de ciências, que possibilitavam prática. A matemática, mesmo com as modificações propostas, não era tão atrativa quanto aquelas disciplinas que possibilitavam "fazer uma experiência prática e depois você estudar aquela coisa [que] você viu" (PRATA, 2010, p.20).

Roberto Senna conta como eram as aulas de ciências durante seu $2^{\circ}$ grau, que cursou a partir de 1973, explicando o funcionamento do "Método dos Passos", que ele considera como sendo "a coisa mais inovadora e mais fantástica" do Colégio de Aplicação (SENA, 2010, p.45):

[...] eu vou te contar uma história, a mais inovadora, mais fantástica, que foi o estudo de química e física. Nós adotávamos aquele livro BSSC da, aliás, da biologia e física, BSSC e o PSSC, pra física, eram livros de autores americanos, mas muito didáticos e tal. Então, tinha um professor americano que tinha um método que chamava de "método dos passos" eu não sei o primeiro nome dele, mas o sobrenome dele era Keller, então era conhecido como método Keller de ensino. Durante os três anos do científico, a gente não tinha prova escrita, a gente não tinha avaliação escrita, nem de biologia, nem de física, você recebia... não tinha aula ministrada presencialmente, os professores no início do semestre entregavam o que eles chamavam de "os passos" e você só recebia um passo de cada vez, então, primeiro passo, aí você tinha todas as instruções, a bibliografia que você tinha que estudar, quais eram os temas que você tinha que estudar, o prazo que você tinha pra estudar, quando você se sentisse apto, você marcava uma entrevista com o professor e você fazia uma entrevista verbal, oral e o professor se julgasse que você estava apto pra passar pro passo seguinte, aí ele lhe entregava a folhinha com outro passo e, se você quisesse, você podia se tornar monitor da matéria, então você podia tomar o passo de um colega do passo anterior.

Anna Cristina Almeida, que estudou no CA de 1967 a 1973, se ocupa em explicar que ter estudado Matemática Moderna, inclusive com a utilização de livros diferentes dos convencionais, era o traço moderno e experimental relacionado ao ensino de matemática no CA. Na ocasião, o faz colocando-o em paralelo com as iniciativas realizadas nas disciplinas 
de ciências experimentais, nas quais a realização de aulas teóricas e práticas despontavam como um diferencial em relação ao que conseguiam comparar com outras instituições escolares da cidade.

[...] aí tinha a questão da matemática, que era a matemática moderna, é, que foi uma grande novidade pra gente, a questão de física, química e biologia, era questão dos passos e, além de passos, tinha laboratório também, que era uma coisa que várias escolas não tinham, então, nós tínhamos muita aula prática de laboratório, que era à tarde...

[...] Eu lembro que quando a gente entrou no Aplicação, estudar Matemática Moderna foi uma novidade enorme, enorme, eram coisas... e eram aqueles livros grandes, que eu acho que eram preparados pela Universidade, não eram comprados em livraria, não, eu acho que era a própria... não tenho mais eles. Mas depois, no decorrer dos anos, eu não sei como as outras escolas fizeram (ALMEIDA, 2010, p. $16,33)$.

Nos trechos acima, as memórias dos ex-alunos ajudam a contextualizar o ambiente em que a proposta da MM se realizou e o que dela ficou para os ex-alunos. Eles a identificaram como vinculada às condições favoráveis da instituição e que, ainda que se realizasse de um modo próprio, se explica dentro do escopo de uma instituição com um projeto modernizador bastante mais amplo. As narrativas dos ex-alunos corroboram o argumento de que o Colégio de Aplicação figura como uma instituição experimental. Segundo eles, os novos métodos, conteúdos, disciplinas, padrões educacionais e até professores (os estagiários), costumavam ser, primeiro, testados no CA e, somente depois de avaliados ali, seriam inseridos nas outras escolas da cidade. Isso lhe atribuía, de certo modo, um papel de agência de modernização e vanguarda ante os padrões educacionais baianos da época ${ }^{7}$.

Desse modo, as modificações no ensino de matemática eram recebidas apenas como mais uma expressão experimental daquela cultura escolar e não iniciativas que a singularizavam no interior da instituição. O contexto cultural do Colégio de Aplicação assume, assim, uma função ativa no processo de implementação das propostas trazidas pelos professores de matemática, contribuindo, favoravelmente, para sua institucionalização, uma vez que essas se somavam a outras tantas iniciativas de caráter experimental que ali estavam sendo praticadas e se intensificaram na década de 1960.

\section{A importância de Maria Augusta Moreno na modernização do ensino de matemática}

\footnotetext{
${ }^{7}$ A cristalização dessa identidade institucional moderna e modernizadora acaba por assumir certa pretensão de que o Colégio teria oferecido um padrão educacional supostamente mais adequado e satisfatório. Para Latour (1994), essa é uma marca importante que aparece nas justificativas associadas a certos processos de modernização e que vem bem a calhar à análise aqui proposta: estou entendendo que o Colégio não foi uma instância de modernização geral da sociedade ou do mundo, mas de si mesmo, de suas práticas e das práticas de seus alunos.
} 
O segundo ponto em que se evidencia a singularidade da contribuição das fontes relativas a ex-alunos é a importância da professora Maria Augusta de Araújo Moreno ${ }^{8}$ na implementação da Matemática Moderna no CA. Na historiografia da educação matemática que vem trabalhando com fontes mais tradicionais, ela tem ocupado um lugar um pouco obscuro, apesar de ser reconhecida sua participação no grupo de professores do CECIBA responsável pela produção de materiais didáticos vinculados à MM na Bahia. (DIAS, 2002; DIAS et al., 2013)

A partir da memória dos ex-alunos, constrói-se para ela um lugar mais expressivo e explica-se, em certa medida, sua participação na modernização da matemática no âmbito do Colégio de Aplicação. Para eles, é inegável o protagonismo dela em função do trabalho que realizou na tentativa de implementar a MM na instituição.

[...] durante os sete anos, somente um, justamente o segundo ano é que eu tive uma outra professora, durante seis dos sete anos a professora foi Maria Augusta, me parece que é Maria Augusta Moreno, o sobrenome dela, também não sei se alguém já lhe passou... ela era uma das professoras que, junto com o professor Omar Catunda, desenvolvia, desenvolvia eh... essa metodologia (FREIRE, 2010, p. 22).

A importância do papel da professora Maria Augusta, indicada aqui pela memória de Raimundo Freire, se evidencia ainda mais em associação com as memórias dos outros entrevistados que também lá estudaram naquele período.

Ela foi a professora de matemática mais identificada à implementação da MM no Colégio de Aplicação: dos catorze entrevistados, nove cursaram disciplinas de matemática no período demarcado e, dentre eles, Maria Augusta foi associada por cinco deles como uma personagem importante na implementação da MM. Eduardo Silva, apesar de não ter cursado disciplina de matemática no período, também fez menção a ela por ter sido seu aluno em aulas particulares durante um dos últimos anos de ginásio 9 .

A atuação dela no Colégio foi, mais de uma vez, referida como uma referência da MM, ao lado de Martha Dantas e de Omar Catunda, uma representante do projeto que estava sendo idealizado na Universidade e implementado no CA, como se nota nos trechos a seguir:

[...] Maria Augusta, ela veio nesse processo aí de Omar Catunda e ela... é como se fosse assim, nós estamos utilizando a inteligência que existe dentro da UFBA e, como Omar Catunda não pode estar aqui dando aula, Maria Augusta... talvez até tenha se incorporado ao processo, trazendo até alguma dinâmica para ensinar isso, de uma maneira mais assim, em sala de aula, talvez... (CARVALHO, 2010, p. 26).

\footnotetext{
${ }^{8}$ Maria Augusta de Araújo Moreno nasceu em 1934, em Ilhéus, mudando-se com a família para Salvador poucos meses após seu nascimento. Cursou o primário nas Escolas Ana Neri e Getúlio Vargas, o ginásio no Ginásio Estadual Severino Vieira, e o científico no Colégio Estadual da Bahia. Cursou Matemática na Universidade da Bahia de 1954 a 1957 (MORENO, 2012). Tornou-se professora assistente do Departamento de Matemática da própria instituição a partir de 1961 (DIAS, 2002).

${ }^{9}$ Os entrevistados também mencionaram que as professoras Iracy e Júlia Leocádio ensinaram matemática no CA no período da MM.
}

Bolema, Rio Claro (SP), v. 30, n. 56, p. 1223 - 1243, dez. 2016 
O reconhecimento da existência dessa parceria entre professores de matemática do Colégio (Maria Augusta) e os professores da Universidade (Omar Catunda e Martha Dantas), que se evidenciava para os alunos também a partir da produção de livros didáticos, propiciava algum tipo de destaque para o ensino de matemática do CA, em comparação com os alunos de outras escolas. "Um delírio", como menciona Valber Carvalho (2010, p.13):

\begin{abstract}
Quando chegamos na sétima série, sétima e oitava, nós tivemos o prazer de estudar, de sermos alunos de uma mulher [...] uma das autoras do livro que a gente estava estudando, você imagina o que significa isso? Maria Augusta, não lembro o resto do nome, não, agora, o livro era feito por oito pessoas, o primeiro, o mais famoso, um matemático daqueles chamado Omar Catunda, e ela era a última ou a penúltima, rapaz, aquilo era um delírio pra gente, a mulher era uma das autoras do livro que a gente tava estudando [...] Martha Maria de Souza Dantas, me lembro de uma, Omar Catunda, que era o primeiro, olhando assim, de certa forma, aquilo era um delírio, né, você conversava com gente, com seus colegas de outros colégios... seu livro de matemática onde sua professora era uma das autoras...
\end{abstract}

Sua memória sugere que essa parceria legitimava, de certo modo, a utilização daqueles livros e a aplicação daquela proposta de ensino de matemática que estava sendo realizada no Aplicação, em função da chancela dos professores da UFBA que tinham participado da produção, tendo entre os membros da equipe um "matemático daqueles" (CARVALHO, 2010, 13)

A atuação de Maria Augusta nesse processo é reconhecida por ela própria, que conta o quanto a proposta que, depois se transformaria em apostilas e livros publicados pelo CECIBA (CAMARGO, 2009), vinha sendo experimentada em suas aulas no Aplicação, enquanto estava sendo produzida: "Nós trabalhávamos, eu e ela [Marta Dantas] trabalhávamos, vamos dizer assim, à tarde e à noite e, de manhã, já tava aplicando. Foi muito assim em cima da perna, então, levei esses meninos até o terceiro ano" (MORENO, 2012, p. 1).

Dessa parceria, Martha Dantas e Maria Augusta foram identificadas nas memórias dos entrevistados como as personagens mais importantes da MM no CA, cada uma a seu modo. Há indícios suficientes para afirmar certo paralelismo entre elas. Se Martha Dantas foi uma das lideranças importantes da $\mathrm{MM}$ da matemática na Bahia, no $\mathrm{CA}$, não se pode negar que Maria Augusta tenha sido apontada como a personagem responsável pela implementação daquele projeto que se realizava no Colégio.

Jaci Menezes, por exemplo, aponta para esse paralelismo entre Maria Augusta e Martha Dantas, ao descrevê-las a partir de traços, tanto físicos quanto de comportamento, que as distinguiam e das diferentes funções que desempenham na Instituição:

Dona Martha era assim, aquela senhora imponente, sempre de salto alto, certo? Presente a vida toda na vida do Colégio e... Maria Augusta era baixinha, um pouco menor, e, assim, ela é elétrica, "The Flash". Ela entrava na sala de aula, ela não fazia mais chamada, então, ela deixou pra lá. "Bom dia, bom dia, bom dia, bom dia...", 
passava pro quadro de giz e passava uma lista de exercício e começava o trabalho, a fazer exposição e, depois, começava o trabalho todo, com exercícios, etc.

[...] Dona Marta, mas ela no Colégio de Aplicação, não sei se ela dava aula nem pro terceiro colegial, nunca me lembro dela ter dado aula aos meus colegas de terceiro ano, não me lembro. [...] ela acompanhava os estagiários, ela era professora da Faculdade, não me lembro dela ter dado aula no Aplicação, não me lembro, pode ser que tenha dado (MENEZES, 2010, p. 4, 17).

Tentando explorar um pouco mais as memórias dos ex-alunos a respeito da atuação de Maria Augusta no processo de modernização da matemática, no âmbito do Colégio de Aplicação, apresento, a seguir, algumas menções às suas práticas didáticas cotidianas.

Por exemplo, com relação aos conteúdos Jaci Menezes recorda que a teoria dos conjuntos foi o primeiro que a professora Maria Augusta introduziu, quando sua turma ingressou no Científico, em 1965: “[...] a gente já começou, eu acho que teve uma primeira unidade, um primeiro mês, que ela trabalhou com algumas apostilas com teoria de conjuntos. É... é uma lembrança fugaz - só pra ela dar, eu acho que era... só pra agilizar conceitos... início..." (MENEZES, 2010, p. 3).

Já Anônima, que ingressou no CA em 1963, lembra que Maria Augusta trabalhou com geometria das transformações em sua turma ainda durante o ginásio:

Era da sétima série e da oitava série que começava com... não era geometria tradicional, era com rotação... simetria, translação e a geometria plana era toda com base nas transformações lin.. nas transformações no plano [...] Maria Augusta era professora de matemática que aplicava (ANÔNIMA, 2010, p. 1).

Acrescento à memória dela a narrativa de Valber Carvalho, que se recorda de como eram as provas de Maria Augusta e como tinha que utilizar o que chamou de "lógica geométrica" para desenvolver os teoremas que apareciam na avaliação (CARVALHO, 2010, p. 9):

[...] as provas dessa professora, Maria Augusta, eram assim: considerando que existem duas retas paralelas que cortam outras duas retas não sei o que lá... e que e o ângulo tal $S 1$ é igual... congruente com o ângulo tal, prove que essa terceira reta que passa aqui é paralela também a essa duas". Você tinha que provar por lógica geométrica. "Com efeito..." - a gente tinha que começar assim -, "com efeito, considerando-se que o ângulo tal é igual ao ângulo tal e que o teorema de não sei quem diz que quando duas retas se cruzam no ângulo tal pa-pa-pa... gera uma terceira reta não sei o quê...", então, pra você responder aquilo você escrevia um catatau de... treze linhas, justificando... até você provar por A mais B, por lógica, que aquele ângulo tal era igual ao ângulo tal. Então, a prova de matemática da oitava série, era assim, era uma prova muito difícil, de escrever, de relacionar teoremas e gerar conclusões, lhe colocava para pensar.

Nota-se, aqui, que Valber Carvalho se refere especificamente à demonstração em uma questão de geometria, indicando uma evidente preocupação com que os alunos aprendessem noções de lógica simbólica e método dedutivo, esses conteúdos e as habilidades desenvolvidas a partir deles eram cobrados dos estudantes pelo menos nas questões de 
geometria citadas, que, pelo que parece, a partir dessa memória, recebia um tratamento axiomático $^{10}$. Ele recorda mais uma das práticas cotidianas nas aulas dela:

[...] ela inventou um sistema de avaliação em que o aluno em todas as aulas tinha que estar presente no início da aula, você não podia faltar e não podia perder o início da aula porque havia um teste, ela chamava de mini-teste ou testinho [...] aquilo era um terror de alguma forma, mas também te mantinha aceso, é como um piloto de avião que tem que fazer teste todo mês pra saber se tá bem, só que era toda aula, e foi um período, assim, muito, mas muito difícil, eu fui muito bem na sétima série, eu me lembro, em equações do segundo grau, e sofri um pouquinho na oitava, que era geometria (CARVALHO, 2010, p. 9).

Maria Augusta conta que aplicava os referidos testes recorrendo à sua intuição "de modo que o acompanhamento do aluno fosse contínuo" (MORENO, 2012, p. 2). Ela os realizava tanto no Colégio de Aplicação quanto no Colégio João Florêncio Gomes, onde também trabalhava, mas seguia um padrão de ensino distinto do realizado no CA. Para ela, o objetivo dessa atividade era fazer com que os alunos se mantivessem continuamente estudando para sua disciplina, o que coincide, de certo modo, com o efeito que a prática causava nos alunos, de acordo com o que contou Valber Carvalho no trecho acima.

Maria Augusta admite que tal prática, sob certo aspecto tecnicista, lhe rendeu a reclamação de alguns pais de alunos insatisfeitos, como conta a seguir:

[...] em todas as aulas eram aplicados pequenos testes numa cadernetinha assim que começava a aula; os testes eram colocados sobre a minha mesa e logo eu ia começando a explicação daquele dia corrigindo simultaneamente os testes. [...] Não demorou muito para que os pais fossem ao SOE, Serviço de Orientação ao Estudante do Colégio de Aplicação, para questionar sobre a atitude dos filhos que alegavam não ter tempo para estudar outra matéria (MORENO, 2012, p. 15).

Tomando como mote essa declaração, abro um parêntese para destacar um elemento que fica evidente na memória da professora, as reações e mecanismos de resistência dos alunos às práticas dos professores de matemática. Aqui, como ela mesma indica, de algum modo, o SOE funcionou como uma instância para onde eram levadas as reclamações, as dificuldades com a disciplina ou com o cumprimento das atividades relacionadas, representando algum limite à sua atuação docente no CA, limite que Julia (2001, p.33) destaca como só podendo ser estabelecido nas relações entre professores e alunos: "De fato, a única restrição exercida sobre o professor é o grupo de alunos que tem diante de si, isto é, os saberes que funcionam e os que "não funcionam" diante deste público".

Os ex-alunos fizeram poucas menções às iniciativas de resistência ao padrão de ensino de matemática que estava sendo praticado. Trago, aqui, uma narrativa que relata reações dos alunos contra a professora de matemática, contada por Jaci Menezes:

\footnotetext{
${ }^{10}$ Em consonância com uma das ideias que orientavam os programas para o ensino de matemática associados à MM, definidas em âmbito internacional (GUIMARÃES, 2007).
} 
Guguta, por exemplo, só falando em Guguta, ela se lembra de uma resistência à implantação das atividades de matemática de uma colega que fumava - nós, na época, as meninas na sala... ninguém fumava na sala, era proibido, mas no intervalo podia fumar, nos corredores não tinha maiores restrições, então, o pessoal tava na porta da sala esperando ela chegar, aí, na hora que ela chegou, essa colega encheu o pulmão e soltou a fumaça no rosto dela, ela... ela ficou ofendidíssima, se sentiu agredida, ela se lembra até hoje! Ela falou pra mim dessa vez que a gente se encontrou, em dezembro do ano passado, "como era o nome daquela sua colega..." eu disse: "eu não me lembro, Maria Augusta", "ah... pois ela encheu o pulmão e soltou a fumaça na minha cara".

Pense numa barreira, assim, uns três ou quatro, na hora dela entrar na sala porque, justamente, o pessoal, esse pessoal que depois passou pro Clássico, no ano seguinte, tava que não aguentava mais de matemática, no regime linha dura de Maria Augusta. Ela fazia com muita naturalidade [...] não é livrando a cara dela, não, ela fazia com muita simpatia, ela dava aula, fazia, preparava... e o pessoal aprendia, tanto assim que eu não sou do ramo e me lembro... (MENEZES, 2010, p. 11-12).

Essa tensão que aparece nas relações entre os alunos do CA e a professora Maria Augusta no CA serve para reforçar a importância de se contemplar a perspectiva dos alunos na produção historiográfica, por indicar aspectos do cotidiano das iniciativas modernizadoras da matemática no Aplicação e que não ocuparam as narrativas dos líderes educacionais, mas que foram marcantes para os alunos e participa da representação que produzem a respeito daquelas propostas.

Por exemplo, Martha Dantas afirmou que não houve prejuízos para os alunos. "A crítica dos professores que executaram a experiência, a reação dos alunos a ela submetidos e as recomendações dos Congressos internacionais que se realizavam, periodicamente, nos ajudaram na tarefa de avaliação do trabalho feito" (DANTAS, 1993, p. 25). Com relação ao CA, as experiências realizadas, a partir de 1966, tiveram êxito, pois, segundo seu entendimento, aqueles que fizeram parte da experiência estavam bem preparados e os alunos que dela participaram tinham condições para utilizar os novos textos.

Com o cotejamento dessas fontes não se chega, propriamente, a uma contradição, mas a um aprofundamento do que vinham a ser as reações dos alunos ou as resistências impostas pelos estudantes às práticas associadas com a MM ali implementadas. A partir da inclusão das representações dos ex-alunos, nota-se que a explicação oficial de que estavam preparados para usar os novos textos é insuficiente para explicar a complexidade de atuação deles, participação ativa no processo de implementação e validação daquela proposta e ignora a riqueza de negociações realizadas para seu desenvolvimento.

Ao contemplar as narrativas dos ex-alunos, ampliamos a representação do contexto social. Ela expressa tensões impostas pelos alunos às aulas de matemática, tanto em função da aprendizagem dos conteúdos quanto em função da metodologia, indicando que, para além de estarem ou não preparados para os textos, a implementação das propostas modernizadoras da 
matemática realizadas no interior do CA, naqueles anos, não funcionou sem negociação com esses sujeitos. Eles exerceram tensões quanto à aprendizagem e à demanda de cumprimento de atividades que lhes eram exigidas em sala, contribuindo para o delineamento da proposta que ali se realizou.

Dizendo de outro modo, a professora não teve liberdade irrestrita para executar sua proposta e não a realizou para si mesma ou cumprindo, sem negociação, aquilo que planejara anteriormente. Ela o fez para um grupo, para uma coletividade que reagia à cada aula, que a tencionava a pensar outras alternativas e que se posicionava ante a suas propostas, fosse na participação durante as aulas ou nas avaliações realizadas.

\section{Concluindo}

Ao considerarmos as narrativas dos ex-alunos do Colégio de Aplicação da Bahia, pode-se notar que se constituem em um material qualificado para a produção historiográfica, permitindo identificar elementos inéditos ou pouco explorados com relação à modernização da matemática ali praticada.

Suas perspectivas indicaram que as iniciativas inovadoras e experimentais propostas pela matemática faziam parte de um projeto maior em que a disciplina estava incluída, apontando para um melhor esclarecimento daquele ambiente escolar e das condições em que a MM se realizou, um clima institucional que contribuiu para que as propostas ligadas à matemática fossem recebidas pelos alunos como inerentes ao projeto do Colégio. Nesse sentido, a matemática não foi interpretada como a disciplina de práticas modernizadoras isoladas, sendo colocada ao lado das iniciativas que vinham sendo implementadas nas ciências experimentais.

As memórias dos ex-alunos também atribuíram um protagonismo, no âmbito do Colégio, à professora Maria Augusta de Araújo Moreno, em função do trabalho que realizou na tentativa de implementar a Matemática Moderna na instituição. A professora foi reconhecida como a representante institucional do projeto que vinha sendo elaborado no âmbito da Universidade e ali executado, ao lado de Martha Dantas.

As memórias dos ex-alunos também contribuíram, apresentando elementos do projeto modernizador da matemática durante em seu processo de execução. Foram indicados mecanismos de negociação e tensão em relação às práticas docentes, algumas estratégias metodológicas utilizadas, quais conteúdos foram mais marcantes e o modo como interpretam o que lhes era exigido que aprendessem. 
Suas contribuições oferecem perspectivas peculiares, representações diferentes das que podem ser lidas ou apreendidas a partir dos materiais publicados pelo CECIBA ou a partir das memórias dos líderes educacionais que o empreenderam. Trabalhar com essas fontes oportuniza o contato com outras representações sociais dos processos educacionais. Como já mencionei, cada grupo produz uma perspectiva diferente e plausível, oferecendo contribuições peculiares que podem enriquecer as versões que vem, tradicionalmente, servindo de fonte para os trabalhos de História da Educação Matemática.

Reiterando o que já foi dito, as fontes relativas a ex-alunos podem ser tomadas como material privilegiado, no caso de investigações que se proponham a compreender os entremeios e correlações das ações dos líderes educacionais e professores, já que, de modo objetivo, apresentam representações que os ex-alunos constroem, explicitando os significados que atribuem a práticas, propostas e conteúdos.

\section{Fontes}

ALMEIDA, A. C. F. Entrevista concedida a Diogo Franco Rios. Salvador, 28 out. 2010.

ANÔNIMA. Entrevista concedida a Diogo Franco Rios. Salvador, 02 nov. 2010.

CARVALHO, V. R. C. Entrevista concedida a Diogo Franco Rios. Salvador, 01 nov. 2010.

DANTAS, M. M. S. Depoimento. Cadernos do IFUFBA, Salvador, v. 6, n. 1/2, p. 11-36, out. 1993.

FREIRE, Raimundo M. de L. Entrevista concedida a Diogo Franco Rios. Salvador, 27 out. 2010.

HISTÓRICO do Colégio de Aplicação da Faculdade de Filosofia da Universidade da Bahia. Centro de Memória da FACED, Universidade Federal da Bahia, Salvador, [1965].

KALIL, M. E. Entrevista concedida a Diogo Franco Rios. Salvador, 05 out. 2010.

MENEZES, J. M. F. de. Entrevista concedida a Diogo Franco Rios. Salvador, 20 dez. 2010.

MORENO, M. A. de A. Entrevista concedida a Diogo Franco Rios. Salvador, 13 fev. 2012.

PRATA, S. Entrevista concedida a Diogo Franco Rios. Salvador, 17 dez. 2010.

COLÉGIO DE APLICAÇÃO DA FACULDADE DE FILOSOFIA DA UNIVERSIDADE DA BAHIA. Regimento do Colégio de Aplicação da F. F. U. B. Centro de Memória da FACED, Universidade Federal da Bahia, Salvador, [1961].

SENNA, Roberto D’A. Entrevista concedida a Diogo Franco Rios. Salvador, 01 nov. 2010.

SERPA, L. F. P. Depoimento. Cadernos do IFUFBA, Salvador, v. 6, n. 1/2, p. 72-76, out. 1993.

SILVA, Eduardo J. S. Entrevista concedida a Diogo Franco Rios. Salvador, 05 dez. 2010. 


\section{Referências}

BARROS, J. D. O campo da história: especialidades e abordagens. Petrópolis: Vozes, 2004.

BERTANI, J. A. Formação de professores de matemática: um estudo histórico comparativo entre Bahia e Portugal (1941-1968). 2012. 217 f. Tese (Doutorado em Ensino Filosofia e História das Ciências) - Universidade Federal da Bahia, Universidade Estadual de Feira de Santana, Salvador, 2012.

BÚRIGO, E. Z. Tradições Modernas: reconfigurações da matemática escolar nos anos 1960. Bolema, Rio Claro, v. 23, n. 35B, p. 277-300, abr. 2010.

CAMARGO, K. C. O ensino da geometria nas coleções didáticas em tempos do Movimento da Matemática Moderna na Capital da Bahia. 2009. 168 f. Dissertação. (Mestrado em Educação Matemática) - Universidade Bandeirante de São Paulo, São Paulo, 2009.

CASSAB, M. A produção em história das disciplinas escolares pela escrita de pesquisadores brasileiros. Revista Brasileira de História da Educação, Maringá, n. 23, p. 225-251, mai./ago. 2010.

CASTROGIOVANNI, A. C. (Org.). Ensino de geografia: práticas e textualizações no cotidiano. Porto Alegre: Mediação, 2000.

CHERVEL, A. História das disciplinas escolares: reflexões sobre um campo de pesquisa. Teoria $\&$ Educação, Porto Alegre, n. 2, p. 177-229, 1990.

DIAS, A. L. M. et al. Martha Dantas. In: VALENTE, W. R. (Org.). Educadoras Matemáticas: memórias, docência e profissão. São Paulo: Livraria da Física, 2013. p. 261-297.

DIAS, A. L. M. Engenheiros, Mulheres, Matemáticos: interesses e disputas na profissionalização da matemática na Bahia (1896 - 1968). 2002. 320 f. Tese (Doutorado em História Social) - Universidade de São Paulo, São Paulo, 2002.

DIAS, A. L. M. O Instituto de Matemática e Física da Universidade da Bahia: atividades matemáticas (1960-1968). História, Ciências, Saúde - Manguinhos, Rio de Janeiro, v. 15, n. 4, p. 1049-1075, out./dez. 2008.

DIAS, A. L. M. O Movimento da Matemática Moderna: uma rede internacional científica-pedagógica no período da Guerra Fria. In: JORNADAS LATINO-AMERICANAS DE ESTUDOS SOCIAIS DAS CIÊNCIAS E DAS TECNOLOGIAS, 1., 2008. Anais... Rio de janeiro: Núcleo de Computação Eletrônica da UFRJ, 2008. p. 1-22.

FOUCAULT, M. A vida dos homens infames. In: O que é um autor? Lisboa: Passagens. 1992. p. 89-128.

FREIRE, I. A. A. Ensino de Matemática: iniciativas inovadoras no Centro de Ensino de Ciências da Bahia (1965-1970). 2009. 102 f. Dissertação (Mestrado em Ensino, Filosofia e História das Ciências) - Universidade Federal da Bahia, Universidade Estadual de Feira de Santana, Salvador, 2009.

FREIRE, I. A. A.; DIAS, A. L. M. Seção Científica de Matemática do CECIBA: propostas e atividades para renovação do ensino secundário de matemática (1965-1969). Bolema, Rio Claro, v. 23, n. 35B, p. 363-386, abr. 2010.

GARNICA, A. V. M. Resgatando oralidades para a história da Matemática e da Educação Matemática brasileiras: o Movimento Matemática Moderna. Zetetiké, Campinas, v. 16, n. 30, p. 163-217, jul./dez. 2008. 
GUIMARÃES, H. M. Por uma Matemática nova nas escolas secundárias: perspectivas e orientações curriculares da matemática moderna. In: MATOS, J. M.; VALENTE, W. R. (Org.). A Matemática Moderna nas Escolas do Brasil e de Portugal: primeiros estudos. São Paulo: Da Vinci, 2007. p. 2145 .

JULIA, D. A cultura escolar como objeto histórico. Revista Brasileira de História da Educação, Campinas, n. 1, p. 9-43. jan./jun. 2001.

LATOUR, B. Jamais fomos modernos: ensaio de antropologia simétrica. Rio de Janeiro: 34, 1994.

LE GOFF, J. Antigo/moderno. In: ROMANO, R. Enciclopedia Einaudi. v. 1, Lisboa: Imprensa Nacional, 1984. p. 370-392.

MATTOS, M. A. PAINEL V - Maria Angélica Mattos Diretora do Colégio de Aplicação (1964 a 1967). In: MENEZES, J. M. F. Experiências Inovadoras na da Bahia. 1. ed. Salvador: Editora UNEB, 2002. v. 2. p. 143-176.

OLIVEIRA, F. F. O School Mathematics Study Group e o Movimento da Matemática Moderna no Brasil. 2009. 201 f. Dissertação (Mestrado em Educação Matemática) - Universidade Bandeirante de São Paulo, São Paulo, 2009.

PASSOS, E. S. Mulheres moralmente fortes: o ideal perseguido pelo Instituto Feminino da Bahia 1945/1955. Revista da FACED, Salvador, n. 0, p. 71-76, 1994.

POLLAK, M. Memória, esquecimento, silêncio. Estudos históricos, Rio de Janeiro, v. 2, n. 3, p. 3-15, 1989.

POLLAK, M. Memória e identidade social. Estudos históricos, Rio de Janeiro, v. 5, n. 10, p. 3-15, 1992.

PORTELLI, A. Ensaios de História Oral. São Paulo: Letra e Voz, 2010.

PORTELLI, A. História Oral como gênero. Projeto História: História e Oralidade, São Paulo, n. 22, p. 9-36, jun. 2001.

RIOS, D. F. Memórias de ex-alunos do Colégio de Aplicação da Universidade da Bahia sobre o ensino de Matemática Moderna: a construção de uma instituição modernizadora. 2012. 505 f. Tese (Doutorado em Ensino, Filosofia e História das Ciências) - Universidade Federal da Bahia, Universidade Estadual de Feira de Santana, Salvador, 2012a.

RIOS, D. F. Contribuições de fontes históricas de ex-alunos para a história do ensino de matemática na Bahia. In: ENCONTRO NACIONAL DE PESQUISA EM HISTÓRIA DA EDUCAÇÃO MATEMÁTICA, 1., 2012, Vitória da Conquista. Anais... Vitória da Conquista: UESB, 2012b. p. 113.

RODRIGUES, A. D. Comunicação e cultura: a experiência cultural na era da informação. Lisboa: Presença, 1994.

THOMPSON, P. R. A voz do passado: história oral. 3. ed. São Paulo: Paz e Terra, 2002.

VALENTE, W. R. A matemática na escola: um tema para a história da educação. In: MOREIRA, D.; MATOS, J. M. (Org.). História do ensino de matemática em Portugal. 1. ed. Lisboa: Sociedade Portuguesa de Ciências da Educação, 2005. v. 1. p. 21-32. 
Submetido em Junho de 2015. Aprovado em Outubro de 2015. 